\title{
Use of primary health services in sparsely populated country districts by patients with musculoskeletal symptoms: consultations with a physician
}

\author{
Kaj E Rekola, Sirkka Keinänen-Kiukaanniemi, Jorma Takala
}

\begin{abstract}
Study objective-To examine the extent to which people consult health centre doctors about various musculoskeletal symptoms and to identify those groups of patients who are responsible for the main workload in primary health care caused by musculoskeletal complaints.

Design-A cross sectional investigation based on case records of people who visited health centre physicians.

Setting-The population of six Finnish health centre districts $(93000$ inhabitants, 64 physicians' posts in primary care centres).

Subjects-6526 patients (7634 visits) who consulted a physician at any of six health centres during a two week period, of which 1380 consulted for musculoskeletal symptoms.

Measurements and main results-The reasons for the visits were abstracted from the case records and were analysed by cross tabulation. The rate of people visiting for musculoskeletal symptoms during a two week period was on average 15 per 1000 inhabitants. It was highest in men aged 45-54 years $(25 / 1000)$ and in women aged 55-64 years (26/1000); the rate fell to the average in men over 54 and women over 64 years. Patients with musculoskeletal symptoms accounted for $21 \%$ of all patients and $27 \%$ of those over 15 years of age. Low back pain was the most common reason for consultation in men aged 25-54 years, while for women aged 35-74 years, the most common reason was neck and shoulder pain.
\end{abstract}

Conclusions-Over one quarter of adults visiting a health centre doctor do so because of musculoskeletal disorders. This fact must be considered when developing health care services and organising basic education and further in-service training for doctors.

F Epidemiol Community Health 1993; 47: 153-157

Health Science and

General Practice,

University of Oulu,

Finland

K E Rekola

$S$ Keinänen-

Kiukaanniemi

Department of

Community Medicine

Community Medicine

University of Kuopio,

Finland

J Takala

Correspondence to:

Dr K E Rekola, Katajati

11, SF-40250 Jyväskylä,
Finland

Accepted for publication October 1992

Pain in and functional disorders of the musculoskeletal system are frequent in all populations studied. ${ }^{1-6}$ In addition to reducing the quality of life, ${ }^{7}$ these are the most common reasons for both short and long term disabilities and for the awarding of disability pensions among the working aged population in industrialised countries, including Finland. ${ }^{8}$ Although only some people with musculoskeletal symptoms visit a doctor, ${ }^{911}$ these symptoms cause a great number of visits, ${ }^{2}$ mostly to primary health services.
Little information exists on the extent to which people visit a doctor for various musculoskeletal symptoms. ${ }^{12-14}$ Researchers have mainly been interested in inflammatory rheumatic diseases, degenerative arthropathies, and in recent years the occurrence and treatment of diseases of the lower back, ${ }^{15}$ although these form only a part of all the diseases causing musculoskeletal symptoms. ${ }^{2} 16$ In the study of primary health services, however, this approach has limitations. Firstly, the diagnostic classification of musculoskeletal disorders is difficult. ${ }^{6} 16$ This is particularly true in primary care where differential diagnosis may be difficult. ${ }^{17}$ Furthermore, because the symptoms are often transitory, a formal diagnosis is not always possible or even necessary. ${ }^{18}$ Thus, it seems reasonable to use symptoms as a starting point when examining how people with musculoskeletal complaints use health care services. ${ }^{10}$ Knowledge of the reasons for consulting a doctor is important when planning the development of health care services. ${ }^{810}$

This investigation examined the extent to which people visit health centre physicians for various musculoskeletal symptoms and to identify those groups of people who are responsible for the main primary health care workload caused by musculoskeletal complaints.

\section{Subjects}

This study concerns the population served by six health centres in central Finland, the combined population base for which is 93000 inhabitants. This represents over one third (37\%) of the total population of the province of central Finland. The age and sex structure of this population is the same as the national average but the occupational distribution shows that farmers represent a larger proportion $(25 \%)$ of the working population than in the country as a whole, with a further $25 \%$ employed in industry and $50 \%$ in the service sector. ${ }^{19}$

The Finnish primary health services are based on a system of health centres owned by the local authorities (communes) or jointly by groups of communes. ${ }^{20}$ Medical care and outpatient serrehabilitation and dentistry. The centres are usually well equipped with laboratory and radiology facilities. All medical records are dictated by physicians and typed by office personnel.

The health centres are situated in small communes composed of both urban and sparsely populated areas. In 1988 the area had an average of one physician's post per 1453 inhabitants in the primary health service, but hardly any private services (only one full time private general 
practitioner and one company doctor). Thus, the population in the area would primarily use its local health centre. Distances to Jyväskylä, the provincial capital, which provides a wider variety of private services, vary between 40 and $170 \mathrm{~km}$.

Table I shows the annual average number of visits to primary health care clinics, hospital outpatient clinics, and private health care in the study population. The frequency of visits to doctors at the health centres varied between $2 \cdot 1$ and $2 \cdot 7$ visits/inhabitant/per year in 1988, while the frequency of visits to private doctors and outpatient departments providing specialist services was considerably lower.

\section{Methods \\ Cases with musculoskeletal symptoms were identified from the case reports of patients who had visited doctors at these six health centres between 15 and 28 February 1988. During these two weeks, 6526 patients made a total of 7637 visits. Oral and written instructions were given to the medical secretaries at the health centres to pick out daily the reports in which the reason for the visit had been symptoms (mostly pain) around the occiput, neck, spine, and various parts of the limbs or muscles. Trauma resulting from direct violence was not included. A preliminary investigation was carried out to examine the reliability of the data acquisition method. Medical secretaries identified $96 \%$ of patients with musculoskeletal symptoms from 100 case reports classified as musculoskeletal cases by the physician (KR). This test suggested that the secretary could identify these patients as well as the physician.}

Table I Annual averages of health services utilisation in the area served by the health centres included in the study (1988)

\begin{tabular}{|c|c|c|c|c|c|}
\hline Health centre & Population & Physicians * & $\begin{array}{l}\text { Health centre } \\
\text { visits/ } \\
\text { inhabitant }\end{array}$ & $\begin{array}{l}\text { Visits to } \\
\text { private doctors/ } \\
\text { inhabitant }\end{array}$ & $\begin{array}{l}\text { Visits to } \\
\text { hospital } \\
\text { outpatient depts/ } \\
\text { inhabitant }\end{array}$ \\
\hline $\begin{array}{l}\text { Äänekoski } \\
\text { Saarijärvi } \\
\text { Keuruu } \\
\text { Viitasaari } \\
\text { Joutsa } \\
\text { Hankasalmi }\end{array}$ & $\begin{array}{r}24339 \\
23493 \\
15223 \\
16802 \\
7047 \\
6096\end{array}$ & $\begin{array}{l}15 \cdot 5 \\
17 \\
11 \cdot 5 \\
11 \\
5 \\
4\end{array}$ & $\begin{array}{l}2 \cdot 3 \\
2 \cdot 2 \\
2 \cdot 7 \\
2 \cdot 7 \\
3 \cdot 1 \\
2 \cdot 8\end{array}$ & $\begin{array}{l}0 \cdot 44 \\
0 \cdot 21 \\
0 \cdot 31 \\
0 \cdot 29 \\
0 \cdot 26 \\
0 \cdot 32\end{array}$ & $\begin{array}{l}0.41 \\
0.44 \\
0.44 \\
0.45 \\
0.44 \\
0.69\end{array}$ \\
\hline Total & 93000 & 64 & $2 \cdot 3$ & 0.31 & $0 \cdot 46$ \\
\hline $\begin{array}{l}\text { County } \\
\text { population }\end{array}$ & 249227 & 162 & $2 \cdot 0$ & $0 \cdot 46$ & 0.52 \\
\hline
\end{tabular}

Musculoskeletal symptoms were classified by one of the authors (KR) according to the anatomical location of the pain. If the visit was occasioned by a number of musculoskeletal symptoms, it was classified according to the first one mentioned. Case reports which had other reasons than musculoskeletal symptoms for the consultation were included regardless of the order of importance.

All patients visiting a health centre doctor for medical care during the investigation period were classified by age and sex from the computer based attendance statistics maintained routinely at the health centres.

\section{METHODS OF ANALYSIS}

The different locations of musculoskeletal symptoms were considered in relation to the total number of patients with any musculoskeletal symptoms and according to sex. The distributions of patients visiting for all reasons and because of musculoskeletal symptoms were compared within each age group using $\chi^{2}$ statistics with correction for continuity. The number of patients visiting a doctor for musculoskeletal symptoms and for each type of musculoskeletal symptom were calculated per 1000 inhabitants by age group and by sex. Finally, the percentage of patients visiting for musculoskeletal symptoms and for each type of musculoskeletal symptom was calculated as a percentage of all patients visiting, by age group and by sex.

\section{Results}

A total of 6526 people visited a primary health care doctor for medical care during the two week period - the total number of visits was 7634 , that is, an average of 1.17 visits/patient. Of these, 1380 (21\%) patients had musculoskeletal symptoms ( $27 \%$ of those over 15 years of age). A total of $47 \%$ of the patients with musculoskeletal symptoms were men.

Figure 1 shows the distribution of the 1380 patients in relation to the different locations of musculoskeletal symptoms and according to sex. Neck pain $(22 \%)$, low back pain $(16 \%)$, and shoulder pain $(14 \%)$ were the commonest reasons for visits to a health centre doctor by women. For men, the lower back $(21 \%)$, neck $(18 \%)$, and
Figure 1: Distribution of patients visiting health centre doctors for different locations of musculoskeletal symptoms grouped by sex.

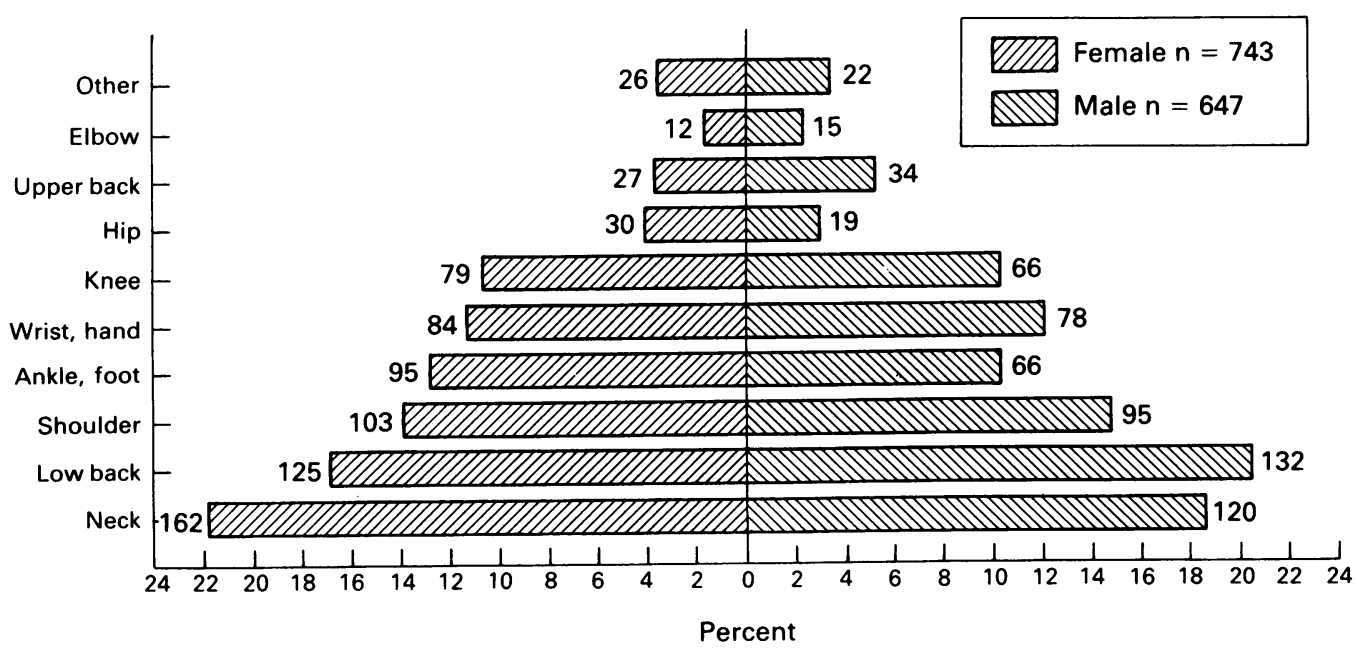


shoulder (14\%) were the most common locations of pain. Thus, these three symptoms accounted for over half of the patients with any musculoskeletal symptoms.

In tables II (men) and III (women), the age distributions of the population at risk, of all patients visiting the health centres during the two week period, and of patients seeking care for musculoskeletal symptoms are shown, and the latter two distributions are compared. The pro-

Table II Age distribution of the male population, all male patients visiting health centres, and male patients seeking care for musculoskeletal symptoms during the study period

\begin{tabular}{|c|c|c|c|c|c|}
\hline \multirow{2}{*}{$\begin{array}{l}\text { Age group } \\
(y)\end{array}$} & \multirow{2}{*}{$\begin{array}{l}\text { Male population } \\
\text { No (\%) }\end{array}$} & \multicolumn{2}{|c|}{ All male patients } & \multicolumn{2}{|c|}{$\begin{array}{l}\text { Male patients with } \\
\text { musculoskeletal symptoms }\end{array}$} \\
\hline & & & & No & $(\%)$ \\
\hline $00-15$ & $9164 \quad(19 \cdot 6)$ & 691 & $(21 \cdot 8)$ & 21 & $(3 \cdot 2)^{\star \star \star}$ \\
\hline $16-24$ & $(14 \cdot 1)$ & 388 & $(12 \cdot 2)$ & 74 & $(11.4)$ \\
\hline $25-34$ & $(15 \cdot 3)$ & 467 & $(14 \cdot 8)$ & 131 & $(20 \cdot 2)^{\star \star \star}$ \\
\hline $35-44$ & (15.9) & 445 & $(14 \cdot 0)$ & 136 & $(20.9)^{\star \star \star}$ \\
\hline $45-54$ & $(11 \cdot 7)$ & 343 & $(10 \cdot 8)$ & 113 & $(17 \cdot 5)^{\star \star \star}$ \\
\hline $55-64$ & $(12 \cdot 1)$ & 371 & $(11 \cdot 7)$ & 93 & $(14 \cdot 3)$ \\
\hline $65-74$ & 3402 & 274 & $(8 \cdot 6)$ & 52 & $(8 \cdot 3)$ \\
\hline $75+$ & $1837 \quad(3.9)$ & 196 & $(6 \cdot 2)$ & 27 & $(4 \cdot 2)$ \\
\hline total & $46772(100.0)$ & 3175 & $(100 \cdot 0)$ & 647 & $(100 \cdot 0)$ \\
\hline
\end{tabular}

$\chi^{2}$ test for difference between age distributions for all patients and musculoskeletal patients $\star \star \star=\mathrm{p}<0.001$

Table III Age distribution of the female population, all female patients visiting health centres, and female patients seeking care for musculoskeletal symptoms during the study period

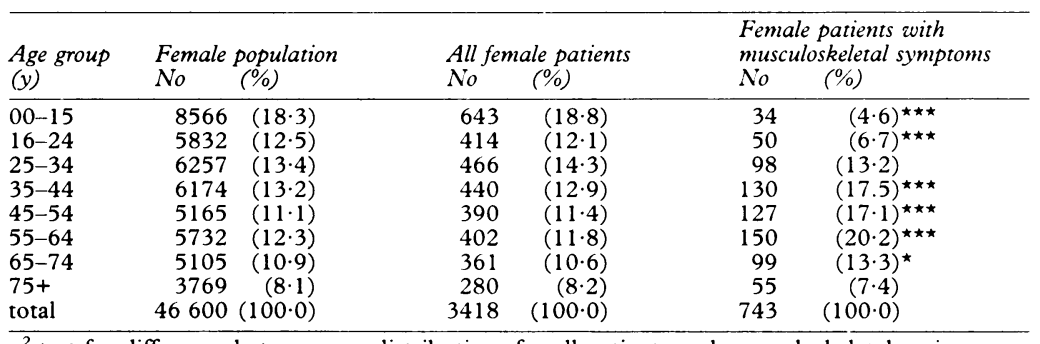

$\chi^{2}$ test for difference between age distributions for all patients and musculoskeletal patients $\star \star \star=p<0.001 ;{ }^{\star}=p<0.05$

Table IV Number of patients per 1000 inhabitants visiting a health centre physician for musculoskeletal symptoms in the study period grouped by age and sex

\begin{tabular}{|c|c|c|c|c|c|c|c|c|c|c|c|c|c|c|c|}
\hline \multicolumn{16}{|c|}{ Age group (y) } \\
\hline \multicolumn{2}{|c|}{$0-15$} & \multicolumn{2}{|c|}{$16-24$} & \multicolumn{2}{|c|}{$25-34$} & \multicolumn{2}{|c|}{$35-44$} & \multicolumn{2}{|c|}{$45-54$} & \multicolumn{2}{|c|}{$55-64$} & \multicolumn{2}{|c|}{$65-74$} & \multicolumn{2}{|c|}{$75+$} \\
\hline $\bar{M}$ & $F$ & $\bar{M}$ & $F$ & $\bar{M}$ & $F$ & $\bar{M}$ & $F$ & $M$ & $F$ & $M$ & $F$ & $\bar{M}$ & $F$ & $M$ & $F$ \\
\hline 2 & 4 & 11 & 9 & 18 & 16 & 18 & 21 & 21 & 25 & 16 & $26^{\star}$ & 16 & 15 & 15 & 15 \\
\hline
\end{tabular}

${ }^{\star}$ Difference between men and women $z=3.652, p=0.001$

Figure 2: Number of people per 1000 inhabitants visiting health centre doctors for different locations of musculoskeletal symptoms, grouped by age and sex.

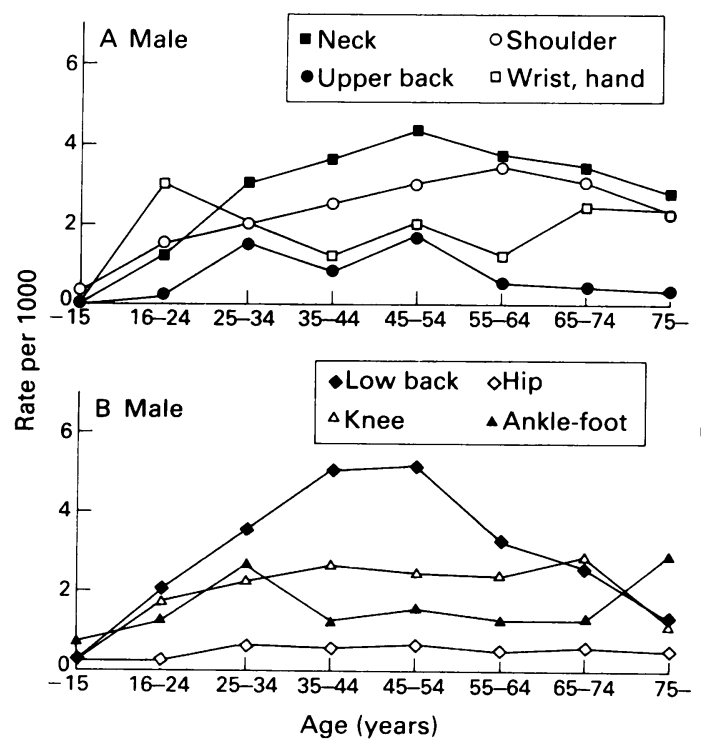

Age (years) portion of men who consulted about musculoskeletal symptoms was greater between 25 and 54 years of age than expected by the age distribution of all male patients, while it was less than expected in men aged 15 years and younger. When the age distribution of all female patients who visited the health centre is considered, the proportion of those seeking help for musculoskeletal symptoms was greater than expected in the 35-74 years group and less than expected in women of 24 years or under.

The number of patients who visited a health centre doctor for musculoskeletal symptoms in the study period per 1000 inhabitants by age and sex is given in table IV. The rates were smallest in people aged 0 to 24 years. The number of visits to a doctor increased with age up to 54 years in men and 64 years in women, after which it decreased. The rate is significantly greater in women then men in the age group 55 to 64 years.

The number of patients per 1000 inhabitants who visited a health centre doctor because of musculoskeletal symptoms in various sites is presented in figure 2 according to age group and sex. For men, the rate associated with low back pain is greatest between 35 to 54 years of age and drops considerably in the older age groups. For neck pain, there is a peak in the group aged 45 to 54 years but the reduction in the older age groups is much less than for low back pain. For women the consultation rate for low back pain peaks in the age group 35 to 54 years, and that for neck pain in ths group 35 to 44 years. There is a noticeable sex difference in the rate of visits for peripheral joint pain: in men there are peaks in both the younger and older age groups, in women the rate is greater for patients aged between 45 and 74 years with shoulder pain and for other peripheral joints in the age group 55 to 64 years.

The percentage of patients who visited a health centre doctor because of musculoskeletal symptoms is presented in table $\mathrm{V}$, according to age and sex. About one third of the patients in the age group 35 to 54 years had musculoskeletal symptoms. The percentage is greatest $(37 \%)$ for women aged between 55 and 64 years. In the age group 16 
Table $V$ Percentage of patients visiting a health centre physician for musculoskeletal symptoms in the study period grouped by age and sex

\begin{tabular}{|c|c|c|c|c|c|c|c|c|c|c|c|c|c|c|c|}
\hline \multicolumn{16}{|c|}{ Age group (y) } \\
\hline \multicolumn{2}{|c|}{$0-15$} & \multicolumn{2}{|c|}{$16-24$} & \multicolumn{2}{|c|}{$25-34$} & \multicolumn{2}{|c|}{$35-44$} & \multicolumn{2}{|c|}{$45-54$} & \multicolumn{2}{|c|}{$55-64$} & \multicolumn{2}{|c|}{$65-74$} & \multicolumn{2}{|c|}{$75+$} \\
\hline $\bar{M}$ & $F$ & $M$ & $F$ & $\bar{M}$ & $F$ & $\bar{M}$ & $F$ & $M$ & $F$ & $M$ & $F$ & $M$ & $F$ & $\bar{M}$ & $F$ \\
\hline$\overline{3}$ & 6 & 19 & 12 & 28 & $20^{\star}$ & 31 & 30 & 33 & 33 & 25 & $37^{\star \star}$ & 20 & $28^{\star \star \star}$ & 14 & 20 \\
\hline
\end{tabular}

to 34 years, the percentage of men seeking care for musculoskeletal symptoms is greater than for women. The opposite situation exists for women in the age group 55 to 74 years.

Figure 3 shows the percentage of patients with different locations of musculoskeletal symptoms in relation to all patients visiting a health centre doctor. The percentages of women with neck pain (9\%) and low back pain (6\%) are largest in the age group 35 to 44 years, while knee and ankle pain are the most common musculoskeletal complaints between 55 and 64 years of age. The percentage of women patients with shoulder pain is greatest between 45 and 74 years of age.

The percentage of men with low back pain (9\%) is greatest between 35 and 54 years of age, declining sharply in older age groups. The percentage of men with wrist pain is greatest between 16 and 24 years of age. The percentage of men with peripheral joint problems is low except for those with shoulder pain which is greatest in the age group 55 to 64 years.

\section{Discussion}

In this study the percentage of all adult patients who visited a doctor because of musculoskeletal symptoms $(27 \%)$ is similar to or greater than those reported in earlier investigations. ${ }^{1014}$ When percentages of visits caused by musculoskeletal symptoms are compared across health care systems, there is more variation (8-14\%), possibly depending on different physicians' practice patterns (proportion of return visits and visits as a result of prevention etc). Another reason may be differences in diagnostic classification. Classification by anatomical site of symptoms, ${ }^{10}$ as in this study, includes problems caused by sprains and strains. These are classified as injuries in the International Classification of Diseases, ${ }^{21}$ and may not be included in some studies, despite the fact, that minor or moderate strains and sprains often precede musculoskeletal pain problems. Stumbo ${ }^{22}$ found that half of all accidents presenting at a rural health centre were sprains and strains. Thus, classification by site of musculoskeletal symptoms seems to quantify better the burden of musculoskeletal illness than classification by diagnosis. ${ }^{10}$

The age distribution of people consulting for musculoskeletal symptoms shows that they are mainly of working age. For men in this study, neck and low back pain and peripheral joint problems are the most common reasons for visiting the doctor because of musculoskeletal pain in the age group 25-34 years. The peak in the percentage of wrist, hand and ankle problems is possibly caused by sports and industrial injuries. Consultation as a result of peripheral joint symptoms seems to become less frequent in middle age, where low back pain is the main reason for visiting the doctor. In middle aged men, it has been suggested that degenerative disc disease is a common reason for low back pain in combination with occupational strain. ${ }^{23}$

Both the rate of the male population seeking care because of musculoskeletal symptoms and the percentage of male patients seeking care for musculoskeletal symptoms drop steeply in men between 55 and 64 years of age, compared with men in the previous age group. There may be several reasons for this unexpected finding, which seems mostly to be attributable to an appreciable drop in patients seeking care for low back pain. Firstly, nearly half of the male population in the age group 55-64 years is receiving a disability pension, the leading cause being musculoskeletal disorders. Thus, this group no longer needs medical certificates for sick leave or treatment for work hindering back pain. Secondly, those who remain employed may be healthier with regard to the musculoskeletal system with less need to seek medical care. The percentage of patients seeking
Figure 3: Patients visiting a health centre doctor for different locations of musculoskeletal symptoms as a percentage of all patients visiting for any reason and grouped by age and sex.
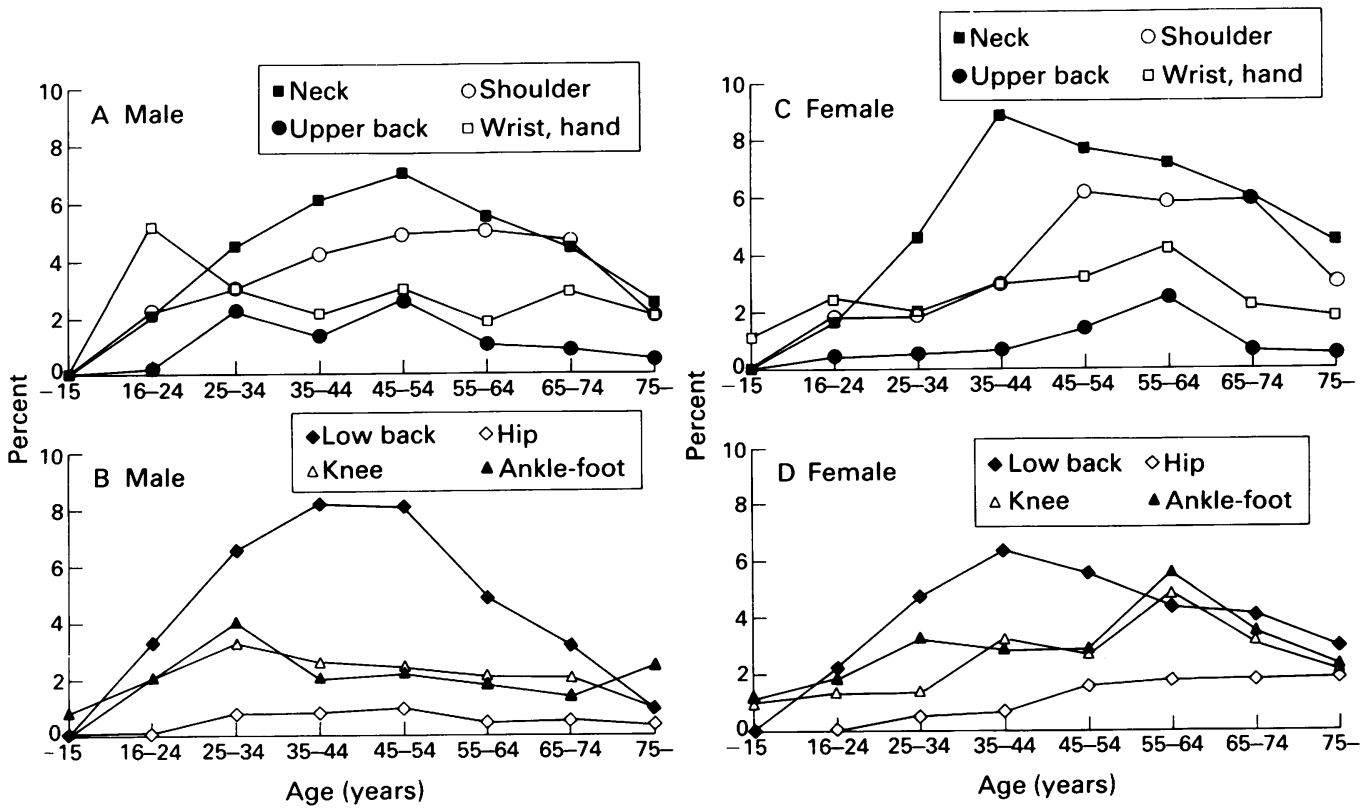
care for musculoskeletal pain reduces with increasing age, which may be related to increasing preoccupation with more serious problems like cardiovascular diseases. Finally, there may be a biological explanation. Degenerative changes in the spine, which become more frequent with increasing age, stabilise vertebral segments that are unstable because of disc disease and thus reduce the incidence of back pain in older people. $^{24}$

For women between 35 and 44 years, neck pain is the most common musculoskeletal complaint seen by the primary care physician. One explanation may be that neck pain is caused by occupational strain. Women in the study area are mostly self employed in agriculture, employed in clothing manufacturing, electronic assembling industries, or clerical work, where the work positions are known to predispose to neck and shoulder pains. ${ }^{25} 26$

While for men in the age group 55-64 years the rate of seeking care because of musculoskeletal disorders drops to the level of men over 64 years of age, women show the greatest rate in this age group. Although the impact of neck and low back pain is less than in the younger age groups, care seeking seems to peak because of peripheral joint symptoms from the arms and legs as well. One explanation may be that pain caused by incipient osteoathrosis or osteoporosis, which hinders manual tasks, standing, and walking, forces women in this age group to seek care. After normal retirement age, 65 years of age, the rate of consultation equals that of men. This pattern may indicate that factors related to employment play a role in care seeking caused by musculoskeletal pain, as it is not reasonable to presume that degenerative joints would become symptomless after the age of 65 years. On the other hand, older people may already be accustomed to their pain and may be more aware of the minimal effectiveness of the treatments available and therefore more reluctant to seek care. ${ }^{27}$

The finding that there were no differences between male and female patients in other than the 55-64 age group in seeking care for musculoskeletal symptoms contrasts with the results of Partridge and Knox. ${ }^{12}$ They found that the overall consulting rate among women in Scotland because of musculoskeletal symptoms was higher than that for men, with the exception of the age group 25-34 years. The rate for women over 65 years was twice that for men over 65 . This difference was not observed in the present study. The reason may be different consulting habits in the population.

These results indicate that low back pain in working age men and neck and shoulder disorders in working age women constitute a considerable part of the work load of doctors in primary health care. The importance of neck and shoulder symptoms as a reason for medical consultation may be increasing as the number of employees in offices and production line work grows. These types of work exert strain on the neck and shoulder area, ${ }^{25}{ }^{26}$ which in the future may cause increasing demands on health services.

Patients with musculoskeletal symptoms inflict high costs on society. Thus, special attention should be paid to them when examining the needs for improving the health care system and the training of doctors. ${ }^{2810}$ Further research is needed to explain why only some people with musculoskeletal symptoms decide to seek medical help. In addition, research should address how doctors in primary health care use diagnostic methods and prescribe treatments for these conditions and how what is actually being done compares with recommendations in the published reports.

We are grateful for financial support from the Research Fund of Central Hospital of Jyväskylä, Finland and The Yriö Jahnsson Foundation. We thank Professor Jennifer Kelsey, Stanford University for valuable comments on earlier drafts of this paper.

1 Rafnsson V, Steinrimsdottir OA, Olafsson MH, Sveinsdottir T. Musculoskeletala besvär bland islänningar. Nord Med 1989; 104: 104-7

2 Wood PHN, Badley EM. Musculoskeletal system. In: Holland Ww, Detels R, Knox G, eds. Oxford handbook of public health. Oxford: Oxford University Press, 1985: public healt $279-97$.

3 Klaukka T, Sievers K, Takala J. Epidemiology of rheumatic diseases in Finland in 1964-76. Scand $\mathcal{F}$ Rheumatol 1982 (suppl 47): 5-13.

4 Cunningham LS, Kelsey JL. Epidemiology of musculoskeletal impairments and associated disability. $A m$ f Publ Health 1984; 74: 574-8.

5 Takala J, Sievers K, Klaukka T. Rheumatic symptoms in the middle-aged population in southwestern Finland. Scand $\mathcal{f}$ Rheumatol 1982; (suppl 47): 15-29.

6 Kelsey JF. Epidemiology of musculoskeletal disorders. New York: Oxford University Press, 1982.

7 Pope GC. Medical conditions, health status and health services utilization. Health Sere Re's 1988; 22: 857-77.

8 Sievers K, Klaukka T, Takala J. Rheumatic disorders in the Finnish health care system in 1964-1976. Scand Rheumatol 1982; (suppl 47): 31-41.

9 Lisdonk Van De EH. Perceived and presented morbidity in general practice. Scand 7 Prim Health Care 1989; 7: 73-8.

10 Spitzer WO, Harth M, Goldsmith $\mathrm{CH}$, et al. The arthritic complaint in primary care: prevalence, related disability and complaint in primary care: prevalen

11 Verbrugge LM, Ascione FJ. Exploring the iceberg. Common Verbrugge LM, Ascione FJ. Exploring the iceberg. Common
symptoms and how people care for them. Med Care 1987;

12 Partridge REH, Knox JDE. Rheumatic complaints in general practice. $f R$ Coll Gen Pract 1969; 17: 144-54.

13 Billings RA, Mole KF. Rheumatology in general practicesurvey in World Rheumatism Year. $\dot{f} R$ Coll Gen Prait 1977 27: $721-25$.

14 Fry J. Common diseases: their nature, incidence and care. 4th ed. Lancaster: MTP Press Limited, 1985.

15 Bjelle A, Allander E, Mägi M. Rheumatic disorders in the Swedish population and health care system. 7 Rhetumato Swedish population

16 Jayson MIV. Difficult diagnoses in back pain. BMIf 1984 288: $740-1$.

17 Brooke JB, Sheldon MG. Clinical decision=patient with problem+doctor with problem. In: Sheldon M, Brooke J, Rector A, eds. Decision making in general practice. New Y York: Stockton Press, 1985: 95-105.

18 Sackett JD, Haynes BR, Tugwell P. Clinical epidemiologv: A basic science for clinical medicine. Boston: Little Brown \& Co, 1985.

19 Finnish population statistics 1988. Central Bureau of Statistics, Helsinki, 1988.

20 Kekki P. Primary Health Care in Finland. In: Fry J, Hasler JC eds. Primary health care 2000. London: Churchill JC eds. Primary health cure
Livingstone, 1986; 201-10.

21 World Health Organisation. Manual of the international statistical classification of diseases, injuries and cause's of death, 9 th revision, vol 1 . Geneva; WHO, 1977

22 Stumbo WG. Musculoskeletal problems profiled from a rural primary care center practice. 7 Kentuck $k$. Med $A s s 1977$ 75: $431-3$

23 Mooney V. Where is lumbar pain coming from? Ann Mled 1989; $21: 373-9$

24 Yong-Hin K, Kirkaldy-Willis WH. The pathophysiology of degenerative disease of the lumbar spine. Orthop Clin North Am 1983; 14: 491-504.

25 Anderson JAD. Shoulder pain and tension neck and their relation to work. Scand $\mathcal{f}$ Work Enciron Health 1984; 10: 435-42

26 Linton SJ, Kamwendo K. Risk factors in the psychosocial work environment for neck and shoulder pain in secretaries. f Occup Med 1989; 31: 609-13.

27 Crombic DL. An assessment of the nursing, medical and social requirements in illness with specific reference to the range of medical care in general practice. Birmingham: University of Birmingham, 1955. (MD thesis). 